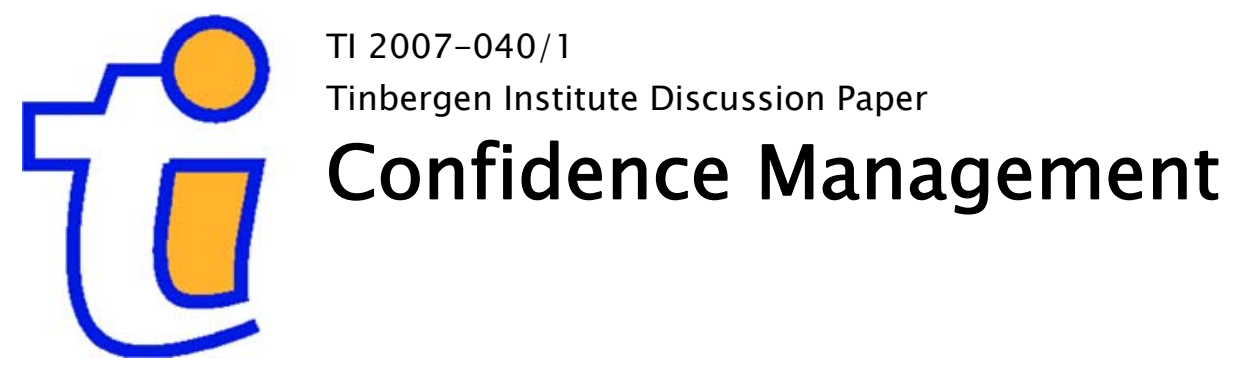

Benoît S.Y. Crutzen

Otto H. Swank

Bauke Visser

Department of Economics, Erasmus University Rotterdam, and Tinbergen Institute. 


\section{Tinbergen Institute}

The Tinbergen Institute is the institute for economic research of the Erasmus Universiteit Rotterdam, Universiteit van Amsterdam, and Vrije Universiteit Amsterdam.

Tinbergen Institute Amsterdam

Roetersstraat 31

1018 WB Amsterdam

The Netherlands

Tel.: $\quad+31(0) 205513500$

Fax: $\quad+31(0) 205513555$

Tinbergen Institute Rotterdam

Burg. Oudlaan 50

3062 PA Rotterdam

The Netherlands

Tel.: $\quad+31(0) 104088900$

Fax: $\quad+31(0) 104089031$

Most TI discussion papers can be downloaded at http:/ /www.tinbergen.nl. 


\title{
Confidence management: on interpersonal comparisons in teams *
}

\author{
Benoît S. Y. Crutzen, Otto H. Swank and Bauke Visser ${ }^{\dagger}$
}

April 11, 2007

\begin{abstract}
Organizations differ in the degree to which they differentiate employees by ability. We analyse how the effect of differentiation on employee morale may explain this variation. By comparing employees using ordinary talk, a manager boosts the self-image of some, but hurts that of others. Whether the net effect is positive for the organization depends on the degree of synergy between employees and on the shape of their objective function. An implication for relative performance pay is that it yields a double dividend or constitutes a double-edged sword.
\end{abstract}

"There's differentiation for all of us in our first 20 years. Why should it stop in the workplace?" (Jack Welch, former CEO of General Electric).

"Comparisons are odious" (William Shakespeare, Much Ado About Nothing)

\section{Introduction}

One of the main tasks of managers is to motivate employees. Managers are trained to act as their mentor and coach, to provide encouragement, and to assess their abilities.

${ }^{*}$ We have benefitted from presentations at the Erasmus School of Economics, European University Institute, University of Essex, the University of Groningen, and HEC Montreal. We are especially grateful to Leon Bettendorf, Pascal Courty, Robert Dur, Mike Gibbs, Maarten Goos, Marco Haan, Giuseppe Moscarini and Karl Schlag for comments and discussions. Bauke Visser gratefully acknowledges the hospitality of the EUI.

${ }^{\dagger}$ Department of Economics, Erasmus University Rotterdam. P.O. Box 1738, 3000 DR Rotterdam. The Netherlands. Emails: crutzen@few.eur.nl; swank@few.eur.nl; bvisser@few.eur.nl. 
The economics literature has much to say about this task. It offers alternative ways of how managers can motivate employees by linking performance and rewards (see Prendergast (1999) and Gibbons (1998) for surveys). Recently, economists have also looked at organizational choices such as the delegation of tasks and job enlargement as ways of motivating employees (Benabou and Tirole, 2003, Swank and Visser, 2007).

So far, economists have paid little attention to the question of how managers can motivate through ordinary talk. In fact, most economists seem quite pessimistic about the scope of verbal communication for motivating employees (see, for instance, Hermalin, 1998, and Fang and Moscarini, 2005). The problem is that a manager who wants an employee to work hard is inclined to exaggerate the importance of tasks or to exaggerate his perception of the employee's abilities. An employee sees through this incentive, and therefore ignores the manager's statements.

Whatever economists say about talk as a motivating device, it is undeniable that it exists. Perhaps the best-known example is the coach prepping his team for an important match. Pep talk is hoped to boost the confidence of the members of the team. Interestingly, in sport two types of coaching can be distinguished. Sometimes a coach addresses the entire team and avoids mentioning differences in abilities of individual members. This is usually the case in team sports like volleyball or hockey or in cheerleading. In her manual on coaching cheerleading, Chappell (2005) states: "[e]ach person on the squads needs to feel special. Avoid making comparisons among squad members." In contrast, some coaches do differentiate members of a team on the basis of ability. This occurs, for instance, in cycling where the members of a team must bring the best cyclist to victory.

The main objective of this paper is to identify the conditions under which a manager differentiates between employees or refrains from doing so. In our paper, differentiating means that a manager says to one employee that he is better than another employee. We develop a model in which a manager who runs a unit in an organization considers whether and how to use differentiation to maximize the value of production of her unit. Our model has three key features. First, the manager has got a more accurate impression of the ability of the people working in her unit than they have themselves. Second, ability and effort are complements in the objective function of both the manager and her employees. Third, we allow for the possibility 
of synergies between the employees. One could say that the group of employees may form a team. Specifically, the effort of an employee may be more productive, and thus the value generated by the unit may be higher, the more able is the other employee and the more effort the other employee expends.

The fact that a manager supervises two (or more) employees changes the nature of possible statements she can make: she can now compare them and make this comparison known to them together. Chakraborty and Harbaugh (2007) show that 'comparative' cheap talk may be credible even if communication between a sender and a single receiver is not. Translated in terms of our model this means that a manager who is not believed when communicating with a single employee may be able to credibly communicate information about her employees' abilities by comparing them with each other publicly.

The main question we address is whether a manager would like to make use of this possibility. What are the costs and benefits of changing the self-image of employees? Suppose the manager observes the ability levels of George and Todd. If she tells that George is more able than Todd, the self-image of the first is boosted, while that of the second is hurt. Motivating George comes at the cost of demotivating Todd, and this makes the manager's statement credible. As a result, George will exert more effort and Todd less, compared with a situation in which the manager refrains from making a comparison. If total effort exerted does not change, the complementarity between individual ability and effort dictates differentiation - the manager benefits from the increased alignment between an employee's ability and effort level. The disadvantage is that in case of strong synergies between employees, the manager would rather shy away from making comparisons to ensure that her employees work equally hard. As we show in the analysis, the latter consideration is particularly important in case both employees are very able. This in turn implies that if the manager refrains from comparing her employees because of the team nature of production in her unit, she signals that both employees are of aboveaverage ability. Abstaining from differentiation, rather than leaving employees in the dark about their abilities, boosts their self-image and provides encouragement.

The manager may be reluctant to differentiate even in the absence of synergies. The way an employee's perception of his ability affects his effort also plays an important role. As an example, suppose that employees already work hard in the 
absence of differentiation and the costs of effort rise rapidly with effort. Boosting one employee's self-image does not induce him to exert considerably more effort, while demoralising the other employee leads to a substantial drop in effort. The total effect on value can be negative. We show that, again, the manager is particularly hesitant to make differences in ability public when her employees are very able. Either employee's self-image is strengthened when the manager refrains from making comparisons.

Our model shows under which conditions managers want to differentiate between employees through ordinary talk. It is important to recognize, however, that differentiation may also take place through other human resource practices. Take pay. It does not make sense to remain silent on differences in abilities on the one hand, but to base rewards on abilities on the other. Motivation through talk and motivation through pay should go hand in hand. This raises the question whether compensation practices are consistent with the predictions of our model.

There is evidence that the more important synergy among employees becomes for the organization, the less the firm pays on the basis of observed performance (ability). Frank (1985) reports that pay of realtors and car salesmen are made visible and highly dependent on performance. To the contrary, pay of a research professor in the sciences is virtually independent of his success at fund raising activity, although success or failure is visible. Consistent with our theory, Frank notes that these professors frequently collaborate. He also notes that wages are flatter in the army than in civilian jobs. Studies of internal labour markets have shown that although performance differences do exert an influence on pay differences, the position held is also very important (Doeringer and Piore, 1971, Baker, Jensen and Murphy, 1988, Baker, Gibbs and Holmstrom, 1994a and 1994b, Gibbs 1994). ${ }^{1}$ Does this mean that good performance is rewarded through promotion? Not always. Seniority and formal rule also play an important role in promotion decisions. In this context, Prendergast (1999) observes that bureaucracy is a central feature of organizations. However, 'fast tracks' - quick promotions for the very able - do exist in internal labour markets,

\footnotetext{
${ }^{1}$ Further evidence comes in the form of the recurrent finding in the literature that performance ratings are very concentrated and skewed to the top, and that the implied premium of being classified one rank higher is small, see e.g. Medoff and Abraham (1980), Flabbi and Ichino (2003), and Dohmen (2004) for case studies, and Armstrong and Stephens (2005) for British survey data. The latter study also shows that the proportion of organizations in the UK that used performance ratings fell from 78 per cent in 1992 to 59 per cent in 2003.
} 
consistent with the prediction of our model that very large differences in ability will be made public. Bewley (1999) interviewed more than 300 businesspeople to answer questions concerning internal pay structures. He was surprised by the extent to which "employers chose to impose bureaucratic constraints on their decision making" (Bewley, 1999, p. 75). In fact, our results are in line with the considerations managers put forward when asked about compensation practises. They mentioned the repercussions of differentiation on internal harmony and morale as the main reason why they were reluctant to distinguish between employees on the basis of their performances.

The fact that bureaucratic rules, in particular seniority, play an important role in promotions is somewhat surprising against the background of the favourable incentive effects competitive compensation schemes like tournaments have. ${ }^{2}$ Tournament theory describes the behaviour of agents competing for a set of prizes (Lazear and Rosen, 1981). Typically, the focus is on the behaviour of agents before the prize is given, and on the effort of the winner. ${ }^{3}$ Our analysis suggests that tournaments also have incentive effects after the prize is given. The reason is that the outcome of a tournament provides information about the agents' abilities: after a tournament the winner is more motivated than the losers. More specifically, if in our model differentiating employees by ability is desirable, a tournament has a double dividend. It motivates before the prize is given, and the balance of motivation and frustration in the aftermath of the contest is positive. If, by contrast, differentiating is undesirable, a tournament is a double-edged sword, as the balance of motivation and demotivation after the prize is given is negative. Demotivation of losers is far from a remote possibility: in Bewley (1999), fear of undermining morale was one of the main reasons managers mentioned to justify their reluctance to differentiate employees on the basis of ability.

The rest of the paper is organized as follows. The next section presents the related literature. Section 3 presents the basic model and Section 4 analyzes the benchmark situation. Next, Section 5 shows why a manager may want to abstain from differentiating employees in the presence of synergies between employees. Section 6 turns to the role of the shape of the employees' objective function. Section 7

\footnotetext{
${ }^{2}$ Chiappori and Salanié (2003) speak of an "empirical puzzle".

${ }^{3}$ Rosen (1986) focuses on survivors in elimination tournaments.
} 
concludes. An appendix contains all the proofs.

\section{Related literature}

Our model belongs to the cheap-talk literature. Crawford and Sobel (1982) were the first to analyse under what conditions cheap talk - costless, non-verifiable statements - between a sender and a single receiver is credible. The better aligned their interests are, the richer the communication between these two can be. Communication lacks credibility if interests diverge too much. Farrell and Gibbons (1989) show that even if communication with a single receiver is not credible, the presence of more than one receiver may make public communication credible. If a firm would like a bank to believe its prospects are excellent to obtain cheap loans, but it wants the unions to think the outlook is bad to reduce wage demands, then even if private communication is not credible, speaking in public may become credible. Chakraborty and Harbaugh (2007) show how the presence of more than one receiver may make communication possible as comparative statements now become feasible. ${ }^{4}$

Our theory also sheds light on how the characteristics of the workplace determine how interpersonal comparisons impact on the morale of 'winners' and 'losers'. Synergy between employees plays a key role. There may be other reasons to refrain from differentiation on the basis of ability, however. Managers may find it hard to break bad news per se (Baker, Jensen and Murphy 1988). Employees' anticipation of an unfair treatment at the moment of appraisal may depress the value of abilitydependent incentives (Armstrong and Stephens 2005). Making promotions depend on (perceived) ability may lead to influence activities that come at the cost of productive activities (Milgrom 1988). If a manager has selected a supervisee, classifying him as unsatisfactory may look bad on the manager. The advantage of our theory is that it better picks up the variation in the degree to which differentiation takes place as reported in e.g. Frank (1985), and that it is consistent with the reason provided by the managers interviewed by Bewley (1999).

We also contribute to the literature on team production. The typical problem addressed in this literature is free-riding by employees. Alchian and Demsetz (1972)

\footnotetext{
${ }^{4}$ Their model is actually cast in terms of multidimensional cheap talk between a sender and a single receiver, see also Levy and Razin (forthcoming).
} 
offer a hierarchical relationship in combination with residual ownership as a solution. Holmstrom (1982) focuses on incentive contracts. Milgrom and Holmstrom (1990) and Auriol, Friebel and Pechlivanos (2002) focus on competition between employees, and warn that it may hinder cooperation. In none of these papers is performance feedback an issue. We focus on feedback, and make two contributions. First, teams allow managers to use cheap-talk messages credibly in order to manage the morale of their teams. Second, we show that managers may not always use such credible messages, not because it hinders cooperation, as in Auriol et al., but rather because of its effects on the morale of the employees.

In our model, because ability and effort are complements, the right effort level requires an understanding of one's ability. Psychologists have paid much attention to a person's desire to obtain accurate self-knowledge from evaluations. ${ }^{5}$ One source of information are other persons' appraisals (Felson, 1993; Baumeister, 1998). A problem is that accurate feedback on abilities is rare (Jones and Wortman, 1973). Feedback tends to be too positive (Brown and Dutton, 1995). These findings are in line with the prediction of our model that managers have incentives to exaggerate the employees' abilities.

Learning from others can only occur in situations of asymmetric information. Others know things about us we do not know ourselves. Recently, Bénabou and Tirole (2003) have explored this idea. They argue in a principal-agent setting that to demonstrate her confidence in an agent's ability, a principal may delegate tasks to an agent or may refrain from helping him (see also Swank and Visser, 2007). Our paper deviates from Benabou and Tirole in our focus on talk as a means of confidence management and our focus on teams.

Finally, others have also addressed the question of the desirability of interpersonal comparisons. Ederer (2004), like us, assumes that a manager is better informed about the performance of her juniors, and that effort and ability are complements. The manager has the option to provide information about the relative scores while they are still competing for a prize. In his paper synergy between juniors is absent, and attention is therefore limited to the shape of the cost of effort function. Furthermore, truthful communication is unproblematic by assumption, whereas in our

\footnotetext{
${ }^{5}$ See, e.g., Trope, 1979; Dunning, 1995; Taylor et al., 1995. Another motive that guides selfevaluations is not accuracy but enhancement - the desire to hold a favorable view of oneself.
} 
paper it is cheap talk. Fang and Moscarini (2005) analyse the effect on morale stemming from wage differentiation. We adopt their individualistic approach to morale: "A worker's morale is interpreted as her confidence in her own ability" (Fang and Moscarini, 2005, pp. 750-51). An important feature of their analysis is that in general agents are overconfident. Workers think they are more able than they really are. Because of the assumed overconfidence, a firm may refrain from differentiating. We do not assume overconfidence. Instead, we show that it is the manager's hesitance to differentiate in case the employees are relatively similar that induces the vast majority of employees to hold a view of their abilities that is better than the ex-ante average ability. Our model also provides an explanation for the fact that some employees hold fairly pessimistic views about their abilities: these are the workers that come out as 'losers' from the manager's differentiation decision. Grund and Sliwka (2005), Bartling (2006), and Ederer and Patacconi (2007) analyse how envy, inequity aversion, and status concerns, respectively, influence the nature and desirability of interpersonal comparisons.

\section{The basic game}

Consider an organizational unit that is led by an experienced manager. In her unit, two juniors $j=1,2$ exert effort, $e_{j}$. They may differ in ability $a_{j}$. The objective function of a junior $j$ equals

$$
V\left(e_{j} ; a_{j}\right)=U\left(e_{j} ; a_{j}\right)-C\left(e_{j}\right)
$$

with $U(\cdot)$ having non-negative partial derivatives and negative second-order partial derivatives, and $C(\cdot)$ being a strictly convex cost function with $C(0)=0$. We think of (1) as a reduced form representation of preferences. The key assumption we make is that the cross-partial derivative of $U(\cdot)$ is positive. This complementarity between effort and ability implies that $e_{j}^{*}\left(a_{j}\right)$, the unique value of $e_{j}$ that maximizes $(1)$, is increasing in $a_{j} \cdot{ }^{6}$

\footnotetext{
${ }^{6}$ It may actually be the case that the objective function of junior $j$ depends on the effort and ability of the other junior. What is important for our results is that, in equilibrium, the total derivative of $e_{j}^{*}$ with respect to $a_{j}$ is positive.
} 
We assume that the manager is interested in maximizing

$$
U_{M}\left(e_{1}, e_{2}, a_{1}, a_{2}\right)=a_{1} e_{1}+a_{2} e_{2}+k a_{1} e_{1} a_{2} e_{2}
$$

One can think of $a_{j} e_{j}$ as a junior's individual performance. The term $k a_{1} e_{1} a_{2} e_{2}$ captures any possible synergy between juniors that matters to the manager. The parameter $k \geq 0$ captures the strength of this synergy. One could say that the manager supervises a group if $k=0$, while she supervises a team if $k>0$. We use the functional form in (2), rather than a more general form like $W\left(e_{1}, e_{2}, a_{1}, a_{2}\right)$, for two reasons. First, it suffices to drive home the point that the presence of more than one junior may enable the manager to make credible statements concerning abilities. Second, it allows us to analyse various reasons why she may want to refrain from doing so.

Essentially, the manager's role is to coach and motivate the juniors. To introduce room for coaching in the simplest way, we assume that the manager, based on years of experience with similar subordinates, knows $a_{1}$ and $a_{2}$. The juniors only know that their abilities $a_{1}$ and $a_{2}$ are draws from iid random variables, with continuous density functions $f(\cdot)$ on $[0,1]$, and associated distribution functions $F(\cdot)$. The timing is therefore as follows. 1) The manager observes $\left.\left(a_{1}, a_{2}\right) ; 2\right)$ she then decides what to tell the juniors (what message $m$ to send); and 3) after observing the message, the juniors decide how much effort to exert.

To solve the game, we look for Perfect Bayesian Equilibria (in pure strategies), in which players' strategies are optimal responses to each other, given the beliefs about abilities, and beliefs are updated according to Bayes' rule wherever possible. In the present type of game babbling equilibria always exists. ${ }^{7}$ We will ignore such equilibria.

A key feature of our model is that the manager coaches two juniors, not one. We now show that this feature widens the scope for credible communication. It is well-known that if there were just one junior in the unit, the manager could not credibly communicate any information about this junior's ability. Suppose the junior were to believe the manager. Then, given the complementarity of effort and

\footnotetext{
${ }^{7}$ In such an equilibrium, the manager's message does not contain information about the juniors' abilities, the juniors ignore the manager's message, and posterior beliefs equal prior beliefs.
} 
ability, the manager would have an incentive to always tell him that his ability level is the highest possible, $a=1$, irrespective of the junior's true ability. The junior sees through this incentive, ignores the manager, and bases his effort decision on his ex ante belief, $\mathrm{E}\left(a_{j}\right)$.

The presence of a second junior expands the nature of statements the manager can make. Besides being able to talk about individual abilities in isolation — statements that will, again, readily be ignored - the manager can now publicly compare juniors. In particular, the manager can use statements in which she publicly, i.e., in front of both juniors together, compares the juniors' abilities by stating "George is more able than Todd". She can also remain silent or at least refrain from making a public comparative statement. To characterize this statement strategy, let $x \succ y$ denote the publicly made statement that junior $x$ is more able than junior $y$, and $x \sim y$ the absence of a comparative statement. The statement strategy of the manager becomes: ${ }^{8}$

$$
S= \begin{cases}1 \succ 2 & \text { if }\left(a_{1}, a_{2}\right) \in K \\ 1 \sim 2 & \text { if }\left(a_{1}, a_{2}\right) \in L \\ 2 \succ 1 & \text { if }\left(a_{1}, a_{2}\right) \in M\end{cases}
$$

where $K, L$, and $M$ are mutually exclusive sets such that $K \cup L \cup M=[0,1] \times$ $[0,1] \backslash\{0,0\} .{ }^{9}$ We assume a natural language, in the sense that statement $1 \succ 2$ does not mean $a_{2}>a_{1}$. Because of the symmetry of the model, ${ }^{10}\left(a_{1}, a_{2}\right)=(a, b) \in K$ if and only if $\left(a_{1}, a_{2}\right)=(b, a) \in M$. For the same reason, junior 2's strategy equals that of junior 1, mutatis mutandis. In what follows, we therefore focus on junior 1 . We therefore drop the subscripts from the equilibrium effort levels. On the basis of a statement strategy $S$, junior 1 updates his beliefs about his ability. Let $F_{1 \succ 2}\left(a_{1}\right)$ denote the distribution function of $a_{1}$ conditional on the manager stating that junior 1 is the more able junior, and similarly for $F_{1 \sim 2}\left(a_{1}\right)$ and $F_{2 \succ 1}\left(a_{1}\right)$. With these beliefs in mind, junior 1 then determines what level of effort to choose. Define the optimal

\footnotetext{
${ }^{8}$ In Section 4, we discuss the implications of a richer message space.

${ }^{9}$ For ease of presentation, we ignore the (uninteresting) possibility that $\left(a_{1}, a_{2}\right)=(0,0)$.

${ }^{10}$ Abilities are drawn from iid distribution functions, $a_{1} e_{1}$ and $a_{2} e_{2}$ can be interchanged in the manager's utility function, and the juniors' utility functions are identical.
} 
effort levels conditional on the manager's statements as

$$
\begin{aligned}
E^{*} & =\arg \max _{e_{1}} \int_{0}^{1} V\left(e_{1} ; a_{1}\right) d F_{1 \succ 2}\left(a_{1}\right), \\
e^{*} & =\arg \max _{e_{1}} \int_{0}^{1} V\left(e_{1} ; a_{1}\right) d F_{1 \sim 2}\left(a_{1}\right), \\
\varepsilon^{*} & =\arg \max _{e_{1}} \int_{0}^{1} V\left(e_{1} ; a_{1}\right) d F_{2 \succ 1}\left(a_{1}\right) .
\end{aligned}
$$

Because of the assumption of a natural language, if the statements $1 \succ 2$ and $2 \succ 1$ are used in equilibrium, then $F_{1 \succ 2}\left(a_{1}\right)$ first-order stochastically dominates $F_{2 \succ 1}\left(a_{1}\right)$. A positive (negative) statement about a junior's relative ability boosts (hurts) his self-image. Therefore $E^{*}>\varepsilon^{*}$. If the messages $1 \succ 2$ and $2 \succ 1$ are used in equilibrium, it cannot be the case that $e^{*}>E^{*}$. If it were the case, the manager would prefer $1 \sim 2$ independently of $\left(a_{1}, a_{2}\right)$ and the statements $1 \succ 2$ and $2 \succ 1$ would not be used. Next, if $L$ is non-empty, that is, if there are values of $a_{1}$ and $a_{2}$ such that $1 \sim 2$ is used in equilibrium, then $e^{*} \geq \varepsilon^{*}$. If the reverse were to hold, the manager would never choose $1 \sim 2$, and so $L$ would be empty. Finally note that for $\left(a_{1}, a_{2}\right)=(a, 0)$, with $a>0$, the manager strictly prefers to state $1 \succ 2$ : absent any means to change junior's 2 individual performance, she prefers to boost junior 1 's morale. Hence, the set $K$ is always non-empty (and by symmetry so is $M$, as $(0, a) \in M$ for $a>0)$. There will always be some degree of differentiation. As we will see below, the set $L$ may be empty.

Contrary to a statement strategy that addresses a single individual, a public ordinal statement strategy is credible because it is not completely costless for the manager to boost one junior's self-esteem: it comes at the cost of demotivating the other junior and possibly of reducing the synergetic value. The next lemma follows from the preceding discussion.

Lemma 1 In any PBE, the manager uses the ordinal statements $1 \succ 2$ and $2 \succ 1$. Thus, $E^{*}>\varepsilon^{*}$. She may also use $1 \sim 2$, in which case $e^{*} \in\left[\varepsilon^{*}, E^{*}\right]$.

Now assume the manager observes juniors' abilities, with $a_{1}>a_{2}$. Given the effort levels in (4) and the manager's objective function in 2, the manager is willing to state $1 \succ 2$ rather than $1 \sim 2$ if and only if

$$
a_{1}\left(E^{*}-e^{*}\right)+a_{2}\left(\varepsilon^{*}-e^{*}\right)>k a_{1} a_{2}\left(e^{* 2}-E^{*} \varepsilon^{*}\right)
$$


The left-hand side of the inequality denotes the change in aggregate individual performance stemming from matching effort and ability. The complementarity of effort and ability implies that the manager would like the more able junior to exert the higher effort level and the less able junior the smaller effort level. For differentiation to be worthwhile, the change in aggregate individual performance should be larger than the change in 'synergetic value' due to differentiating between juniors. From this inequality it follows that the manager's willingness to differentiate depends on three factors, besides the observed ability levels: the degree of synergy between juniors, and, through the effort levels, the objective function of the junior and the ex ante distribution of abilities.

Clearly, condition (5) amounts to saying that, for the manager to prefer boosting junior 1's effort at the cost of junior 2's effort, $a_{2}$ should be sufficiently low:

$$
a_{2}<h_{-}\left(a_{1} ; k\right)=a_{1} \frac{E^{*}-e^{*}}{e^{*}-\varepsilon^{*}+a_{1} k\left(e^{* 2}-E^{*} \varepsilon^{*}\right)} .
$$

Analogously, for sufficiently high values of $a_{2}, a_{2}>h_{+}\left(a_{1} ; k\right)$, the manager prefers $2 \succ 1$ over $1 \sim 2$. The functions $h_{-}$and $h_{+}$are each other's mirror image in the main diagonal. It is easy to check that $h_{-}(0 ; k)=h_{+}(0 ; k)=0$, and that the functions are increasing in $a_{1} \cdot{ }^{11}$ Concerning the manager's desire to differentiate (rather than abstain from doing so) three observations can be made. First, if for a given value of $a_{1}, h_{-}\left(a_{1} ; k\right)<h_{+}\left(a_{1} ; k\right)$ holds, then the manager prefers not to differentiate among juniors for $a_{2} \in\left(h_{-}\left(a_{1} ; k\right), h_{+}\left(a_{1} ; k\right)\right)$. That is, if the manager abstains from differentiation, she does so for ability levels that are 'comparable', or 'near' and on the main diagonal. Second, if $h_{+}\left(a_{1} ; k\right)<h_{-}\left(a_{1} ; k\right)$ for some values of $a_{1}$, then the manager claims differences between juniors exist, even if they are equally able. For $a_{1}>a_{2}$, the manager prefers to boost junior 1's self-esteem at the cost of junior 2's, and vice versa for $a_{2}>a_{1}$. In case $a_{1}=a_{2}$, the manager strictly prefers differentiation over no differentiation, but she is indifferent between stating that junior 1 is better than junior 2 or vice versa. ${ }^{12}$ Finally, if abstaining from differentiation leads to a higher synergetic value, $e^{* 2}-E^{*} \varepsilon^{*}>0$, then $h_{-}$is

\footnotetext{
${ }^{11} h_{-}^{\prime}\left(a_{1} ; k\right)=\frac{(E-e)(e-\varepsilon)}{\left(e-\varepsilon+a_{1} k\left(e^{2}-E \varepsilon\right)\right)^{2}}>0$.
}

${ }^{12}$ In other words, as soon as $h_{+}\left(a_{1} ; k\right)<h_{-}\left(a_{1} ; k\right)$ for some values of $a_{1}$, these functions lose their relevance in defining the borders of $K$ and $M$ : the relevant border is a section of the main diagonal. 
concave in $a_{1}$ (and so $h_{+}$is convex) for $k>0 .{ }^{13}$ In this case, the manager is less likely to differentiate the higher are observed abilities, and the stronger are synergies $k$.

\section{A benchmark case}

We start by presenting a situation in which the manager makes full use of the possibility to differentiate by publicly comparing the juniors. That is, we describe a benchmark situation in which the manager desires to make any difference in ability public. She weakly prefers not to make any public ordinal statement only if juniors are equally able. This situation can then be used to understand any reason for the manager to either shy away from differentiation or to claim non-existing differences to be present. The benchmark is defined as follows.

Definition 1 In the benchmark case, synergies are absent from the manager's objective function $(k=0)$, a junior's objective function equals $V\left(e_{j} ; a_{j}\right)=a_{j} e_{j}-\frac{1}{2}\left(e_{j}\right)^{2}$, and the distribution of abilities is uniform on $[0,1]$.

The PBE of the benchmark case consists of a statement strategy $S_{B}$ that equals

$$
S_{B}= \begin{cases}1 \succ 2 & \text { if } a_{1}>a_{2} \\ 1 \sim 2 & \text { if } a_{2}=a_{1} \\ 2 \succ 1 & \text { if } a_{2}>a_{1}\end{cases}
$$

Consistent with $S_{B}$, the ex post beliefs for junior 1 equal

$$
\mathrm{E}\left(a_{1} \mid 1 \succ 2\right)=2 / 3, \quad \mathrm{E}\left(a_{1} \mid 1 \sim 2\right)=1 / 2, \quad \mathrm{E}\left(a_{1} \mid 2 \succ 1\right)=1 / 3 .
$$

It follows from the junior's objective function that optimal effort levels equal the expected ability conditional on the public statement of the manager. Hence, given (8), optimal effort levels become$$
E_{B}^{*}=\mathrm{E}\left(a_{1} \mid 1 \succ 2\right), e_{B}^{*}=\mathrm{E}\left(a_{1} \mid 1 \sim 2\right) \text {, and } \varepsilon_{B}^{*}=\mathrm{E}\left(a_{1} \mid 2 \succ 1\right) .
$$$$
{ }^{13} h_{-}^{\prime \prime}\left(a_{1} ; k\right)=-k\left(E^{*}-e^{*}\right)\left(e^{* 2}-E^{*} \varepsilon^{*}\right) \frac{2\left(e^{*}-\varepsilon^{*}\right)}{\left(e^{*}-\varepsilon^{*}+a_{1} k\left(e^{* 2}-E^{*} \varepsilon^{*}\right)\right)^{3}}<0 \text { for } e^{* 2}-E^{*} \varepsilon^{*}>0 \text { and }
$$
$k>0$. 
Because of the juniors' beliefs and the quadratic costs, $E_{B}^{*}-e_{B}^{*}=e_{B}^{*}-\varepsilon_{B}^{*}$, i.e., the increase in effort of junior 1 thanks to differentiation is as large as the reduction in effort of junior 2. It then follows from (5) that in the absence of synergetic effects the manager prefers stating $1 \succ 2$, rather than $1 \sim 2$, if $\left(a_{1}-a_{2}\right)\left(E_{B}^{*}-e_{B}^{*}\right)>0$. This implies that when $a_{1}=a_{2}$, the manager is indifferent between any of the three statements. As soon as she observes $a_{1}>a_{2}$, the manager wants to differentiate. This shows that $S_{B}$ is a best reply to the juniors' strategies. Note that if the manager avoids comparative statements a junior's self-image is left unaffected, $\mathrm{E}\left(a_{1} \mid 1 \sim 2\right)=$ $\mathrm{E}\left(a_{1}\right)$.

Proposition 1 In the benchmark case, the manager publicly compares the two juniors as soon as she observes a difference in ability. If the manager refrains from making comparative statements, because $a_{1}=a_{2}$, a junior's self-image is left unaffected.

Before we analyse reasons why the manager may not want to differentiate even though she has observed differences in abilities, three remarks are in order. First, the optimality of the statement strategy $S_{B}$ in $(7)$, in which the manager reveals any difference in ability she observes, does not depend on the distribution of abilities being uniform. To see this, consider any continuous density $f$, and note that if the manager uses $S_{B}, E^{*}$ equals the expected value of a random variable, the density of which equals the density of the maximum of two iid variables, $E^{*}=\int_{0}^{1} a \cdot 2 F(a) f(a) d a$, whereas $\varepsilon^{*}$ is based on the density of the minimum of two iid variables, $\varepsilon^{*}=\int_{0}^{1} a \cdot 2(1-F(a)) f(a) d a$. Because $e^{*}=\int_{0}^{1} a f(a) d a$, one finds that $E^{*}-e^{*}=e^{*}-\varepsilon^{*}$, independently of $f$. This implies that $S_{B}$ is an equilibrium strategy for any $f$. However skewed or concentrated the distribution of abilities may be (because of organizational selection and/or screening procedures), the result of Proposition 1 is valid: the manager wants to differentiate as much as possible. We choose to include the uniform distribution as part of the specification of the benchmark case because we use this distribution rather than a general distribution function $F$ when analysing the role of synergy and the junior's objective function in the manager's desire to differentiate.

The second remark deals with the message space the manager uses. So far, we have assumed that the senior can send three messages. Do our results change if 
we allow for a richer message space? To answer this question, first suppose that, in addition to comparative statements, the manager can make statements about the juniors' individual abilities. Evidently, in that case, the manager would have strong incentives to exaggerate the juniors' abilities. For example, the senior could say "There is no escaping, George is more able than Todd, but the two of you are both really able". Of course, the juniors see through such additional statements and ignore them. More interesting is to allow for statements like "George is $\alpha$ times as good as Todd", with $\alpha \geq 1$. Although the latter statement leads to the same boost in George's self-esteem as "George is more able than Todd", it does so at a higher cost. If juniors believe these statements, then, with uniformly distributed abilities, $\mathrm{E}\left(a_{1} \mid a_{1}>\alpha a_{2}\right)=2 / 3$ and $\mathrm{E}\left(a_{2} \mid a_{1}>\alpha a_{2}\right)=1 /(3 \alpha) \leq 1 / 3$. The reason is that the latter statement with $\alpha>1$ says more about junior 2 than junior 1 . In particular, $a_{1}>\alpha a_{2}$ excludes that $a_{2}>\frac{1}{\alpha}$. The manager wants to avoid to hurt Todd's beliefs about his ability unnecessarily. We conjecture that the most costefficient way of credibly boosting 1's self-image is by making simple comparative statements like $1 \succ 2$.

Finally, it is worth mentioning that more than two juniors would possibly affect the opportunities for communication. In general, the more juniors there are, the better the senior can tailor effort levels to each junior's ability.

\section{Synergies between juniors}

In this section, the characteristics of the juniors are still as in Definition 1 above, but we allow the manager to value synergies, $k>0$ [see (5)]. For what ability levels does the manager differentiate? The statement strategy in case of synergy can be written as

$$
S=\left\{\begin{array}{l}
1 \succ 2 \text { if } a_{2}<h_{-}\left(a_{1} ; k\right) \\
1 \sim 2 \text { if } a_{2} \in\left[h_{-}\left(a_{1} ; k\right), h_{+}\left(a_{1} ; k\right)\right] \\
2 \succ 1 \text { if } a_{2}>h_{+}\left(a_{1} ; k\right) .
\end{array}\right.
$$

In the Appendix we show that in equilibrium $h_{-}\left(a_{1} ; k\right)$ is concave and lies below the diagonal. It is convenient to explain the intuition behind the statement strategy with the help of the figure below. 


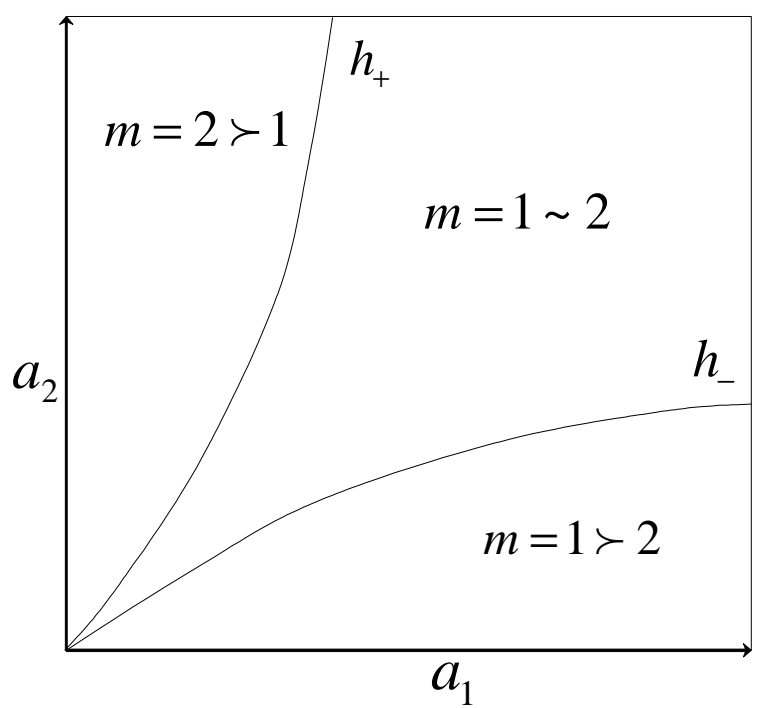

Figure 1: Statement strategy of the manager in the ability space

Figure 1 illustrates two important features of the statement strategy. First, the more $a_{1}$ deviates from $a_{2}$, the more inclined is the manager to differentiate. Second, the more able both juniors are, the more the manager tends to eschew comparisons. Both features highlight that the manager faces a dilemma when deciding whether or not to differentiate. On the one hand, as in the benchmark case, a manager wants to differentiate in order to properly match effort and ability. This relates to the first feature. On the other hand, in the present case, the manager wants to exploit synergy between the juniors. This gives an incentive to the manager to abstain from differentiation. As the synergetic value increases in $a_{1}$ and $a_{2}$, higher values of $a_{1}$ and $a_{2}$ weaken the manager's incentive to differentiate. This explains the concavity of $h_{-}\left(a_{1} ; k\right)$ and relates to the second feature of Figure 1.

Figure 1 is also helpful to understand how the manager's statement strategy affects the two juniors' beliefs about their abilities. Since the manager abstains from differentiation for high values of $a_{1}$ and $a_{2}$, not differentiating boosts the juniors' confidence in their abilities. The flip side of the coin is that $1 \succ 2$ severely damages junior 2's perception of his ability.

The exact location of $h_{-}\left(a_{1} ; k\right)$ [and therefore of $h_{+}\left(a_{1} ; k\right)$ ] depends on $k$. Obviously, the higher is $k$, the more important is synergy between the juniors for the manager, and the weaker is the incentive to differentiate. 


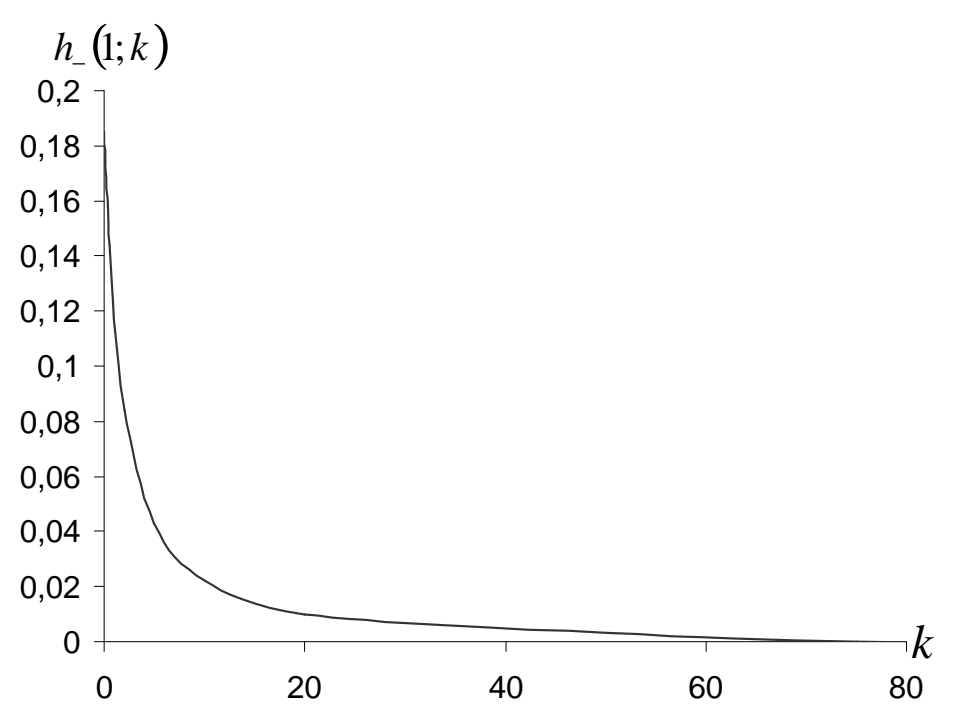

Figure $2: h_{-}(1 ; k)$ as a function of $k$

Figure 2 illustrates how the value of $h_{-}(1 ; k)$ falls with any increase in $k$. Recall that in the benchmark case synergy is absent and the manager differentiates as soon as a difference in ability is observed. Hence, $h_{-}(1 ; 0)=1$. In the absence of synergy, if the manager does not differentiate all ability levels are equally likely. To the contrary, as discussed above, in the presence of synergy, high ability levels become more likely if the manager does not differentiate. As a result, even in case of a very small degree of synergy, say $k=0.001,1 \sim 2$ leads to a strong boost in self-image, and thus in effort. The implication is that a small value of $k$ leads to a large downward jump in the value of $h_{-}(1 ; k)$.

Proposition 2 Consider the benchmark case, and allow for synergies between juniors. The stronger is the degree of synergy, the more likely it becomes that the manager refrains from comparing juniors. Not comparing juniors boosts there selfesteem.

\section{The junior's value function}

What is the influence of the shape of a junior's value function on the statement strategy of the manager? To answer this question, we assume that abilities are uniformly distributed, and that synergies between juniors are absent from the manager's objective function. It follows from (5) that a manager who observes $\left(a_{1}, a_{2}\right)$ would 
like to state that 1 is better than 2 rather than not differentiating if $a_{1}\left(E^{*}-e^{*}\right)+$ $a_{2}\left(\varepsilon^{*}-e^{*}\right)>0$. This condition can be rewritten as

$$
\left(a_{1}-a_{2}\right)\left(E^{*}-e^{*}\right)>a_{2}\left(2 e^{*}-\left(\varepsilon^{*}+E^{*}\right)\right)
$$

The left-hand side of the equation can be read as the benefits of differentiation. As $E^{*} \geq e^{*}$, the larger is the difference in ability, the more attractive differentiation becomes. The right-hand side captures any costs that may result from differentiation. Whether such costs exist depends on the way differentiation affects the total level of effort exerted by the juniors. If the total remains the same, the manager wants to differentiate as soon as she observes a difference in ability. If, however, differentiation reduces the total level of effort, that is, if $2 e^{*}>\varepsilon^{*}+E^{*}$, then in equilibrium the manager refrains from differentiation when ability differences are small. The larger the drop in total effort, the more often she will refrain from differentiating. Moreover, she will be more hesitant to state that 1 is better than 2, the more able is junior 2. As a result, the absence of differentiation boosts either junior's belief about his ability relative to his prior belief. Finally, if differentiation increases total effort, that is, if $2 e^{*}<\varepsilon^{*}+E^{*}$, a manager publicly claims differences to exist although they are absent in reality.

Various aspects of juniors' value functions may determine how differentiation affects total effort. Here we focus on the convexity of the cost of effort function. Specifically, let

$$
V\left(e_{j} ; a_{j}\right)=a_{j} e_{j}-\frac{1}{n}\left(e_{j}\right)^{n} .
$$

The family of cost functions $C(e ; n)=\frac{1}{n}\left(e_{j}\right)^{n}$ is parametrized by $n \in \mathbb{R}$, with $n>1$. Within this family, $n$ can be interpreted as a degree of convexity. The higher is $n$, the more convex the cost function is. It follows from (11) that

$$
e_{j}^{*}=\left(\mathrm{E}\left(a_{j} \mid m\right)\right)^{\frac{1}{n-1}}
$$

If costs are quadratic, marginal costs are linear. As a result, in equilibrium, what the manager gains in effort by boosting one junior's belief about his ability equals what she looses by demoralising the other junior. In other words, total effort is left unaffected by differentiation. 
If costs are less than quadratic in effort $(1<n<2)$, the gain in effort $E^{*}-e^{*}$ thanks to boosting one junior's effort exceeds the drop in effort $e^{*}-\varepsilon^{*}$ due to demoralising the other junior. As a result, differentiation increases total effort, and the manager claims that differences exist even if $a_{1}=a_{2} \cdot{ }^{14}$ She is however indifferent as to who she will tell to be the better junior. Assume that junior 1 is the lucky one. The statement strategy becomes

$$
S= \begin{cases}1 \succ 2 & \text { if } a_{1} \geq a_{2} \\ 2 \succ 1 & \text { if } a_{2}>a_{1},\end{cases}
$$

and ex post beliefs equal

$$
\mathrm{E}\left(a_{1} \mid 1 \succ 2\right)=\frac{2}{3}, \mathrm{E}\left(a_{1} \mid 2 \succ 1\right)=\frac{1}{3} .
$$

Finally, if costs are more than quadratic in effort, $n>2$, total effort goes down as a result of differentiation. Define $\gamma:=\frac{e^{*}-\varepsilon^{*}}{E^{*}-e^{*}} . \gamma$ is the ratio of the reduction in effort due to demoralisation and the increase in effort stemming from a strengthened self-esteem. The statement strategy becomes

$$
S^{\prime}= \begin{cases}1 \succ 2 & \text { if } a_{2}<a_{1} \frac{1}{\gamma} \\ 1 \sim 2 & \text { if } a_{2} \in\left[a_{1} \frac{1}{\gamma}, a_{1} \gamma\right] \\ 2 \succ 1 & \text { if } a_{2}>a_{1} \gamma\end{cases}
$$

Consistent with $S^{\prime}$ are the following beliefs for junior $1:{ }^{15}$

$$
\mathrm{E}\left(a_{1} \mid 1 \succ 2\right)=\frac{2}{3}, \quad \mathrm{E}\left(a_{1} \mid 1 \sim 2\right)=\frac{1}{2}+\frac{1}{6 \gamma} \text {, and } \mathrm{E}\left(a_{1} \mid 2 \succ 1\right)=\frac{1}{3 \gamma} .
$$

As in the previous section, not differentiating among juniors induces either of them to hold beliefs that are more positive than their priors, $\mathrm{E}\left(a_{i} \mid 1 \sim 2\right)>\mathrm{E}\left(a_{i}\right)=\frac{1}{2}$ for $i=1,2$. Figure 3 illustrates the statement strategy for $n>2$ (as $n$ increases, the $h_{-}$line becomes flatter and the $h_{+}$steeper).

\footnotetext{
${ }^{14}$ The effort level $e^{*}$ is based on the plausible out-of-equilibrium belief $\mathrm{E}\left(a_{1} \mid 1 \sim 2\right)=\frac{1}{2}$.

${ }^{15}$ Derivations can be found in the Appendix.
} 


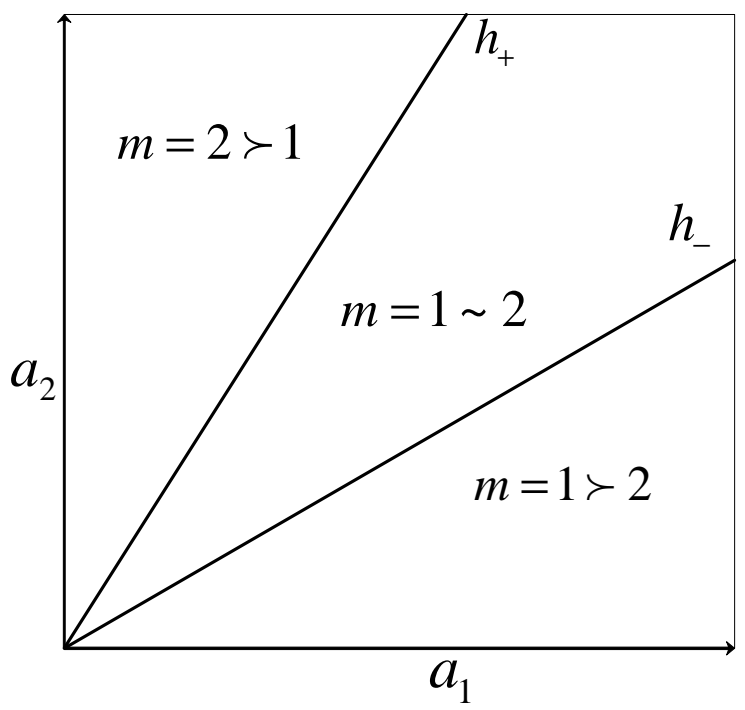

Figure 3: Statement strategy for $n>2$

Figure 4 shows the relationship between the degree of convexity of the cost function $n$ and the value of $\gamma$. For values of $n>2$, the more convex the costs are, the larger is $\gamma$, and so the larger the area around the $a_{1}=a_{2}$-diagonal for which the manager refrains from publicly comparing juniors, see (15).

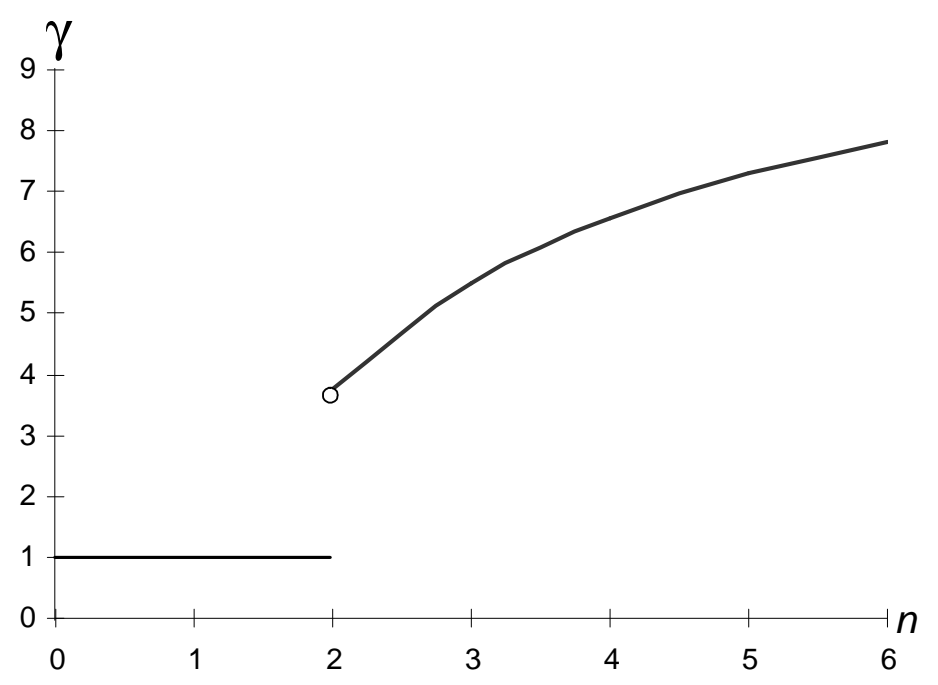

Figure 4: $\gamma$ as a function of $n$

Turning to the relationship between the degree of convexity of the cost function and the belief a junior holds in case the manager does not differentiate, for $1<$ $n<2, \mathrm{E}\left(a_{1} \mid 1 \sim 2\right)=\mathrm{E}\left(a_{1}\right)$ is an out-of-equilibrium belief as a manager always differentiates. For $n=2, \mathrm{E}\left(a_{1} \mid 1 \sim 2\right)=\mathrm{E}\left(a_{1}\right)=1 / 2$, as a manager refrains from differentiating only if $a_{1}=a_{2}$. As we increase $n$ above $2, \mathrm{E}\left(a_{1} \mid 1 \sim 2\right)$ first makes 
a discrete jump from $\frac{1}{2}$ to $\frac{2}{3}$, and subsequently decreases in $n$. This is because if costs are slightly more convex than quadratic, then in equilibrium $2 e^{*}>\varepsilon^{*}+E^{*}$. It then follows from (10) that a manager refrains from differentiating in particular for values of $a_{2}$ close to one (and $a_{1}>a_{2}$ ). This statement strategy strengthens a junior's self-esteem in case public comparisons are absent. And this in turn explains that $2 e^{*}>\varepsilon^{*}+E^{*}$. With increasing levels of convexity, the manager also shies away from differentiating for increasingly lower absolute ability levels, which explains the subsequent decline of the posterior belief. The next proposition summarises the results of this section.

Proposition 3 Consider the benchmark case, but with $V\left(e_{j} ; a_{j}\right)$ defined as in (11). For $1<n<2$, the equilibrium is described by (12), (13), and (14). In particular, the manager always claims that juniors differ in ability, even if they are equally able. For $n=2$, one obtains the benchmark, see Section 4. For $n>2$, the equilibrium is described by (12), (15), and (16). The more convex the cost function is, the larger the area for which the manager refrains from revealing differences among juniors. Also, for $n>2$, not differentiating among juniors boosts their beliefs.

\section{Concluding Remarks}

This paper studies the pros and cons of differentiating employees by ability. The model developed here focuses on situations in which the effort an employee exerts depends positively on his perception of his ability. A key aspect of our model is that inter-personal comparisons lead to higher effort levels of the more able, but to lower effort levels of the less able. We identify three features of the environment that may affect an employer's decision whether or not to differentiate on the basis of ability: synergies between the employees, the convexity of the cost of effort function, and the realized abilities.

A higher degree of synergies weakens the incentive for the employer to differentiate. One implication of this result is that employers are reluctant to differentiate when total performance depends on the "weakest link" in the team. In such a situation, the benefit of boosting the morale of the more able is unlikely to exceed the cost of undermining the morale of the weakest link. 
A higher degree of convexity of the cost of effort function also reduces the employer's inclination to differentiate. As an illustration of the relevance of this finding, take a situation in which employees already work hard without differentiating. For instance, one could think of medical specialists in hospitals. Then, differentiating is more likely to demotivate the less able rather than induce the more able to work much harder. The net-effect of differentiating in such a situation is likely to be negative.

Throughout the paper, we have seen that the more the realized abilities of the employees differ, the more the employer is inclined to differentiate. We have argued that the driving force behind this result is that differentiating leads to better matches between the abilities of employees and their effort levels. Notice that the nature of this last feature deviates from the nature of the first two. The first two may help us to explain why differentiation varies across different types of organizations. Realized abilities are important for understanding variation of differentiation for a given type of organization. For example, realized abilities may help us answer the question why some hospitals differentiate specialists on the basis of ability, while others do not.

\section{Appendix}

In this Appendix, we first show that the function $h_{-}(\cdot)$ that figures in the equilibrium statement strategy $S$ of the manager in case of synergy is concave, lies below the diagonal, and that $e^{*}>1 / 2$. We then derive the expressions in (16).

We show that in equilibrium and for any $k>0, h_{-}\left(a_{1} ; k\right)$ is concave and lies below the diagonal if and only if $e^{*}>1 / 2$. To see the 'if' part, note that the ex ante expected ex post ability equals $1 / 2$ :

$$
\operatorname{Pr}(K) \mathrm{E}\left(a_{1} \mid 1 \succ 2\right)+\operatorname{Pr}(L) \mathrm{E}\left(a_{1} \mid 1 \sim 2\right)+\operatorname{Pr}(M) \mathrm{E}\left(a_{1} \mid 2 \succ 1\right)=\mathrm{E}\left(a_{1}\right)=\frac{1}{2} .
$$

This can be rewritten as $\operatorname{Pr}(K) E^{*}+(1-2 \operatorname{Pr}(K)) e^{*}+\operatorname{Pr}(K) \varepsilon^{*}=\frac{1}{2}$, or as

$$
\varepsilon^{*}=\frac{1}{2 \operatorname{Pr}(K)}-\frac{1-2 \operatorname{Pr}(K)}{\operatorname{Pr}(K)} e^{*}-E^{*} .
$$

Now view $E^{*} \varepsilon^{*}$ as a function to be maximized in $E^{*} . E^{*} \varepsilon^{*}$ is maximized for $E^{*}=v$, 
with

$$
v:=\frac{1}{4 \operatorname{Pr}(K)}-\frac{1-2 \operatorname{Pr}(K)}{2 \operatorname{Pr}(K)} e^{*}
$$

Furthermore, at the maximum, $E^{*}=\varepsilon^{*}$. A sufficient condition for $e^{* 2}-E^{*} \varepsilon^{*}>0$ is $e^{* 2}-v^{2}>0$ or $e^{*}-v>0$. From (17) it follows that $e^{*}-v=\left(e^{*}-\frac{1}{2}\right) /(2 \operatorname{Pr}(K))$, which is positive for $e^{*}>1 / 2$. From footnote 13 , we know that $e^{* 2}-E^{*} \varepsilon^{*}>0$ implies concavity. To show that $h_{-}$lies below the main diagonal, it is sufficient to prove that $h_{-}^{\prime}(0 ; k)<1$ for all $k$. Note that $h_{-}^{\prime}(0 ; k)=\left(E^{*}-e^{*}\right) /\left(e^{*}-\varepsilon^{*}\right)$ and $h_{-}^{\prime}(0 ; 0)=1$. With $e^{*}>1 / 2$, and, because of the concavity, $E^{*}<2 / 3$ and $\varepsilon^{*}(k)<1 / 3, h_{-}^{\prime}(0 ; k)<h_{-}^{\prime}(0 ; 0)$ for all $k$. The 'only if' part is straightforward: if $h_{-}\left(a_{1} ; k\right)$ is concave and lies below the diagonal, then $\mathrm{E}\left(a_{1} \mid 1 \sim 2\right)>\mathrm{E}\left(a_{1}\right)$, and so $e^{*}(k)>1 / 2$. QED.

We now derive the expressions in (16).

$$
\mathrm{E}\left(a_{1} \mid 1 \succ 2\right)=\frac{\int_{0}^{1} \int_{0}^{a_{1} \frac{1}{\gamma}} a_{1} d a_{2} d a_{1}}{\int_{0}^{1} \int_{0}^{a_{1} \frac{1}{\gamma}} d a_{2} d a_{1}}=\frac{2}{3}, \mathrm{E}\left(a_{1} \mid 2 \succ 1\right)=\frac{\int_{0}^{\frac{1}{\gamma}} \int_{a_{1} \gamma}^{1} a_{1} d b d a}{\int_{0}^{\frac{1}{\gamma}} \int_{a_{1} \gamma}^{1} d a_{2} d a_{1}}=\frac{1}{3 \gamma}
$$

and

$$
\mathrm{E}\left(a_{1} \mid 1 \sim 2\right)=\frac{\int_{0}^{\frac{1}{\gamma}} \int_{a_{1} \frac{1}{\gamma}}^{a_{1} \gamma} a_{1} d a_{2} d a_{1}+\int_{\frac{1}{\gamma}}^{1} \int_{a_{1} \frac{1}{\gamma}}^{1} a_{1} d a_{2} d a_{1}}{\int_{0}^{\frac{1}{\gamma}} \int_{a_{1} \frac{1}{\gamma}}^{a_{1} \gamma} d b d a+\int_{\frac{1}{\gamma}}^{1} \int_{a_{1} \frac{1}{\gamma}}^{1} d a_{2} d a_{1}}=\frac{1}{2}+\frac{1}{6 \gamma}
$$

\section{References}

Alchian, Armen A. and Harold Demsetz (1972), "Production, Information Costs and Economic Organization", American Economic Review 62: 777-795

Armstrong, Michael, and Tina Stephens (2005), A Handbook of Employee Reward Management and Practice. London: Kogan Page.

Auriol, Emmanuelle, Guido Friebel and Lambros Pechlivanos (2002), "Career Concerns in Teams", Journal of Labor Economics 20: 289-307

Baker, George P., Michael C. Jensen and Kevin J. Murphy, (1988), "Compensation and Incentives: Practice vs. Theory", Journal of Finance 43: 593-616.

Baker, George, Michael Gibbs and Bengt Holmström (1994a), "The Internal Economics of the Firm: Evidence from Personal Data", Quarterly Journal of Economics 
109: 881-919.

Baker, George, Michael Gibbs and Bengt Holmstrom (1994b). "The wage policy of a firm", Quarterly Journal of Economics, pp. 922-955

Bartling, Björn (2006). "Relative vs. Team Performance Evaluation with Inequity Averse Agents", University of Munich.

Baumeister, R. F. (1998). The self, in: Gilbert, D. T., Fiske, S. T. and Lindzey, G., eds, The Handbook of Social Psychology, New York: McGraw Hill, pp. 680-740.

Bénabou, Roland and Jean Tirole (2003), Intrinsic and Extrinsic Motivation, Review of Economic Studies, 70, 489-520.

Brown, J. D. and Dutton, K. A. (1995). Truth and consequences: The costs and benefits of accurate self-knowledge, Personality and Social Psychology Bulletin, vol. 21 (12), pp. 1288-1296.

Bewley, Truman F. (1999), Why Wages Don't Fall During a Recession. Cambridge, MA: Harvard University Press.

Chakraborty, Archishman and Rick Harbaugh (2007), "Comparative Cheap Talk", Journal of Economic Theory 132: 70-94.

Chappell, Linda R. (2005). Coaching Cheerleading Successfully. 2nd edition, Human Kinetics Publishers Inc.

Chiappori, Pierre-André and Bernard Salanié (2003). "Testing Contract Theory: A Survey of Some Recent Work," in Advances in Economics and Econometrics, ed. by M. Dewatripont, L. Hansen, and S. Turnovsky, pp. 115-149. Cambridge University Press.

Crawford, V. P. and Sobel, J. K. (1982). Strategic information transmission, Econometrica, vol. 50 (6), pp. 1431-1451.V

Doeringer, Peter B. and Michael J. Piore (1971), Internal Labor Markets and Manpower Analaysis. Lexington, Mass.: Heath.

Dohmen, Thomas (2004). "Productivity, seniority and wages: formal salary systems and individual earnings profiles", Labour Economics, pp. 741-763.

Dunning, D. (1995). Trait importance and modifiability as factors influencing selfassessment and self-enhancement motives, Personality and Social Psychology Bulletin, vol. 21 (12), pp. 1297-1306. 
Ederer, Florian (2004). "Feedback and Motivation in Dynamic Tournaments", MIT. Ederer, Florian and Andrea Patacconi (2007). "Interpersonal Comparisons, Status and Ambition in Organizations", MIT.

Fang, Hanming and Giuseppe Moscarini (2005), "Morale Hazard", Journal of Monetary Economics 52: 749-777.

Farrell, Joseph and Robert Gibbons (1988), "Cheap Talk with Two Audiences", American Economic Review 79: 1214-1223.

Felson, R. B. (1993). The (somewhat) social self: How others affect self-appraisals, in: J. Suls (ed.), Psychological perspectives on the self, Volume 4: The Self in Social Perspective, Hillsdale, New Jersey: Lawrence Erlbaum Associates, pp. 1-27.

Flabbi, Luca and Andrea Ichino (2001). "Productivity, seniority and wages: new evidence from personnel data", Labour Economics, pp. 359-387.

Frank, Robert H. (1985), Choosing the Right Pond: Human Behavior and the Quest for Status. New York etc.: Oxford University Press.

Gibbs, Michael (1994) "An Economic Approach to Process in Pay and Performance Appraisals", working paper Graduate School of Business, Chicago.

Gibbons, Robert (1998). "Incentives in Organizations". Journal of Economic Perspectives 12, pp.115-132.

Grund, C. and D. Sliwka (2005). "Envy and Compassion in Tournaments", Journal of Economics and Management Strategy 14 (1): 186-216.

Hermalin, Benjamin E. (1998), "Toward an Economic Theory of Leadership: Leading by Example", American Economic Review 88: 1188-1206.

Holmstrom, Bengt (1982), "Moral Hazard in Teams", Bell Journal of Economics 13: $324-40$

Holmstrom, Bengt and Paul Milgrom (1990), "Regulating Trade Among Agents", Journal of Institutional and Theoretical Economics 146: 85-105

Hutchens, Robert M. (1989), "Seniority, Wages and Productivity: A Turbulent Decade", Journal of Economic Perspectives: 49-64.

Jones, E. E. and Wortman, C. (1973). Ingratiation: An attributional approach, Morristown, NJ: General Learning Press. 
Lazear, Edward (1979). "Why is there mandatory retirement?", Journal of Political Economy, pp. 1261-1284.

Levy, Gilat and Ronny Razin (forthcoming). "On the Limits of Multidimensional Cheap Talk: A Comment", Econometrica.

Medoff, James L. and Katherine G. Abraham (1980), "Experience, Performance and Earnings", Quarterly Journal of Economics 95: 703-736.

Milgrom, Paul (1988). "Employment Contracts, Influence Activities, and Efficient Organizational Design", Journal of Political Economy 96 (1), pp. 42-60.

Prendergast, Canice (1999), "The Provision of Incentives in Firms", The Journal of Economic Literature 37: 7-63.

Rosen, Sherwin (1986), "Prizes and Incentives in Elimination Tournaments", American Economic Review 76 (4): 701-715.

Swank, O.H. and B. Visser, 2007, Motivating through Delegating Tasks or Giving Attention, Journal of Law, Economics and Organization, forthcoming.

Taylor, S. E., Neter, E. and Wayment, H. A. (1995). Self-evaluation processes, Personality and Social Psychology Bulletin, vol. 21 (12), pp. 1278-1287.

Trope, Y. (1979). Uncertainty-reducing properties of achievement tasks, Journal of Personality and Social Psychology, vol. 37 (9), pp. 1505-1518.

Welch, John F. (2001), Jack. Straight from the Gut. New York: Warner Books. 